\title{
Convergence of the epidemiology and pathology of COPD
}

\author{
J Vestbo, J C Hogg
}

The epidemiology of chronic obstructive pulmonary disease (COPD) has been dominated by one hypothesis stating that cigarette smoking and chronic bronchitis were the key to pathogenesis and another that asthma, chronic bronchitis, and even emphysema are related to different expressions of a primary airway abnormality. The first hypothesis was rejected in the late 1960s based on a longitudinal study of working men where only a fraction of smokers developed COPD and where development of COPD was independent of the absence or presence of chronic bronchitis. Chronic bronchitis in more advanced COPD was subsequently associated with a more rapid decline in lung function and more frequent exacerbations. The second hypothesis is more difficult to test but longitudinal studies have shown that the presence of bronchial hyperresponsiveness may predict the subjects who go on to develop COPD. This brief review attempts to reconcile these findings with the pathology found in the lung.

See end of article for authors' affiliations

.....................

Correspondence to: Professor J Vestbo, Department of Cardiology and Respiratory Medicine, Hvidovre University Hospital, Kettegaard Alle 30, DK-2650 Hvidovre, Denmark; joergen. vestbo@hh.hosp.dk

Received 4 May 2005 Accepted

21 September 2005
Thorax 2006;61:86-88. doi: 10.1136/thx.2005.046227

based on responses to the validated British Medical Council questionnaire on cough and phlegm, ${ }^{67}$ with the inherent weakness that any mucus that is not expectorated will not be registered as phlegm. Nevertheless, Fletcher and associates set out to test the British hypothesis in a seminal epidemiological study of working men from West London conducted from 1961 to 1969 and summarised in an important monograph in $1976 .{ }^{8}$ In appendix E of that monograph the authors state that: "It was not until 1967 that we realised that a considerable proportion of men with airflow obstruction had no evidence of mucus hypersecretion and could not, by the Medical Research Council definition, be considered to have obstructive bronchitis." Based on these findings, the authors offered the alternative explanation that "emphysema and intrinsic disease of the small airways were involved to different degrees in these obstructed men".

The data of Fletcher et al showed that the symptoms of chronic mucus hypersecretion in the absence of airflow limitation-now classified as COPD GOLD stage 0 -was a benign condition that did not progress to COPD, and the Copenhagen City Heart Study ${ }^{9}$ confirmed this observation. In this study the odds ratio for developing COPD after 5 and 15 years when comparing the presence and absence of chronic mucus hypersecretion was $1.1(0.9-1.4)$ and 1.2 (0.9-1.6), respectively, after adjusting for age, sex and smoking. However, the Copenhagen database $^{10}$ also showed that mucus hypersecretion was associated with a decline in forced expiratory volume in 1 second $\left(\mathrm{FEV}_{1}\right)$ when subjects with more advanced COPD were included. The effect was seen in both men and women and was stronger for chronic mucus hypersecretion than for occasional phlegm. A recent report on the pathology of small airway obstruction in $\mathrm{COPD}^{11}$ suggests that a shift from an innate to an adaptive immune response in severe (GOLD 3 ) and very severe (GOLD 4) COPD might contribute to this change by driving the inflammatory/remodelling process and increasing fixed airway obstruction at this stage of the disease. Furthermore, other reports have shown that the later stages of COPD are associated with an increased frequency of lower respiratory tract infections ${ }^{12}$ and with chronic sputum production and an accelerated decline in $\mathrm{FEV}_{1}{ }^{13}{ }^{14}$ Both bacterial and viral infection can cause exacerbations, ${ }^{15}{ }^{16}$ bacterial colonisation has been related to a decline in $\mathrm{FEV}_{1}{ }^{17}$ and Banerjee et al postulated that the decline in $\mathrm{FEV}_{1}$ resulted from a chronic low grade inflammatory response to the presence of bacteria. ${ }^{18}$ These results are consistent with the hypothesis that inhaled toxic 
gases and particles damage the lung's innate defence system in the early stages of the disease by reducing mucociliary clearance, producing an ineffective cough, disrupting the epithelial barrier, and initiating an acute on chronic inflammatory process in the distal lung. Although the microbial colonisation and/or repeat infections that are common in the later stages of the disease probably account for most of the adaptive immune response in GOLD stages 3 and 4, it has been argued that this response might also be attributed to autoimmune disease. ${ }^{19}{ }^{20}$ New knowledge about the nature of the signals that link the innate and/or adaptive immune response to the repair and remodelling process would be helpful as multivariate analysis of the pathology data suggests that thickening of walls and restriction of the lumen of the small airways were most strongly associated with airflow limitation. ${ }^{11}$

Fletcher et al used the term "mucus hypersecretion" rather than chronic bronchitis because the pathologists working at that time were unable to define an association between bronchial inflammation and gland enlargement in the post mortem specimens they studied, possibly because of the interference of preterminal events associated with death. However, subsequent studies of lung tissue removed at surgery $^{21} 22$ showed that excess sputum production was associated with a chronic inflammatory process that involved the epithelial lining of the airway lumen, glands, and gland ducts of the central airways of these patients. Moreover, these studies also showed that the lesions in the central airways in chronic bronchitis were independent of the presence of airflow limitation. ${ }^{21}$ Collectively, these pathological features of the disease fit with the epidemiology reported from both London and Copenhagen showing that chronic bronchitis is a benign disease early in the course of COPD (GOLD 0-1), presumably because the innate host defences remain more or less intact, whereas the same symptoms are ominous in the later stages of the disease (GOLD 3-4) when the airways become colonised and infected. Recent studies have found that subjects with chronic mucus hypersecretion have an increased use of health care, ${ }^{23}$ and in the NHANES dataset they had a small excess overall mortality of borderline statistical significance. ${ }^{24}$ We do not think, however, that this implies a role for chronic mucus hypersecretion in the early stages of COPD.

\section{EMPHYSEMA AND SMALL AIRWAYS}

Fletcher et al tried to assess the contribution of emphysema to airflow limitation based on plain chest radiographs obtained from 568 of the men in their study. However, they gave it up when it became apparent that observations based on an agreed grading system for the radiological assessment of emphysema severity could not be reproduced by two eminent radiologists who examined the films independently on two separate occasions (appendix D). ${ }^{6}$ This left the diagnosis and quantification of emphysema in the hands of pathologists willing to take a quantitative approach to the study of the post mortem lungs until the introduction of computed tomographic (CT) scanning. These post mortem studies established that approximately $40 \%$ of smokers have some emphysema in their lungs when they die, and that this ranged from $15 \%$ in the third decade to a peak of $60 \%$ in the seventh and falling back to $50 \%$ in the ninth decade. ${ }^{25}$ They also showed that the volume of total lung taken up by emphysema was $0-70 \%$ in smokers and $0-40 \%$ in nonsmokers. Subsequent studies of surgically resected specimens have shown that substantial amounts of emphysema can be present in patients with normal lung function, ${ }^{26}$ but the relevance of this early emphysema to the natural history of COPD needs to be clarified. Although CT scanning ${ }^{27}$ and MRI imaging of hyperpolarised gas ${ }^{28}$ have provided much more sensitive and specific imaging tools to assess emphysema, they have not been used in studies of the natural history of COPD. One CT based clinical trial has assessed the effect of replacement therapy on the progression of the emphysema in $\alpha_{1}$-antitrypsin deficiency, ${ }^{29}$ but the cost of the scans, the fairly widespread disagreement about the precise boundary that separates fully expanded normal lung from early emphysema, and the radiation dose required for repeated scans in longitudinal studies remain problematical.

The importance of small airway obstruction to airflow limitation in COPD was first suggested by an influential report by Macklem and Mead in $1967^{30}$ which showed that the smaller airways $(<2 \mathrm{~mm}$ internal diameter) account for only $10-15 \%$ of the total resistance to airflow in the normal canine lung. This was subsequently confirmed in both post mortem human lungs ${ }^{31}$ and in living patients, ${ }^{32}$ and although another group ${ }^{33}$ disputed the finding of very low peripheral resistance in the normal lung, all three agreed that the major site of resistance in COPD is in the smaller conducting airways. Mead ${ }^{34}$ suggested that these airways represented a "quiet zone" in the normal lung where considerable disease might be present before airflow limitation would be discovered using standard tests of pulmonary function. An intense period of investigation followed, based on the hypothesis that early detection and treatment of peripheral airway disease would prevent progression. However, the results were unhelpful because the tobacco smoking habit causes some degree of peripheral lung inflammation and abnormal small airway function in everyone and only a small number actually progress to full blown COPD. ${ }^{35}$ Therefore, like the symptoms of chronic bronchitis, tests for small airways disease fell out of favour because they could not predict which smokers with normal lung function would go on to develop severe COPD.

\section{THE DUTCH HYPOTHESIS}

A different hypothesis was put forward by a group from Groningen led by Professor Orie who introduced the term "chronic non-specific lung disease" in 1961. ${ }^{36}$ Their approach, termed the "The Dutch hypothesis", introduced the concept that the airways obstruction associated with asthma, chronic bronchitis, and even emphysema is related to different expressions of a primary abnormality in the airways. The precise nature of this abnormality is difficult to define, but the idea that different disease phenotypes might result from a variation in the host response to the toxic gases and particles present in tobacco smoke is attractive because it could explain why only a fraction of smokers of the same age and sex who have smoked equivalent amounts develop COPD. Pathology based studies provided some support for this hypothesis by showing an amplified inflammatory immune response in the small airways ${ }^{11}$ and lung parenchyma ${ }^{37}$ of smokers with late stage (GOLD 3 and 4) COPD compared to those with similar smoking histories who maintain normal lung function. In both Dutch epidemiological studies ${ }^{38} 39$ and the NIH sponsored Lung Health Study ${ }^{40}$ bronchial hyperresponsiveness was the most important predictor of further decline in lung function, and it has also been shown to be a predictor of vital prognosis. ${ }^{41}$ The problem is that it is difficult to know if hyperresponsiveness initiates the early disease or if early disease initiates the changes that cause airway hyperresponsiveness. None of the mechanisms put forward to explain hyperresponsiveness are easy to investigate and the hypothesis is still regarded as controversial. Nevertheless, smokers with self-reported asthma have a more rapid decline in $\mathrm{FEV}_{1}$ than smokers without asthma, pointing to features of asthma being a predictor of susceptibility. ${ }^{42}$ However, when carefully examined, there are significant differences in both the physiology and airways cytology between patients 
with fixed airflow obstruction derived from chronic asthma and patients with "classical" COPD. ${ }^{43}$ Nevertheless, the Dutch hypothesis resonates with the concept that COPD is a complex genetic abnormality in which products of certain genes or groups of genes interact with environmental stimuli to produce an excessive response that results in disease. The identification of a disease marker capable of predicting the type of response to the inhalation of toxic gases and particles that results in COPD could lead to more precise studies of the natural history and response to treatment of COPD patients. ${ }^{44}$

\section{CONCLUSIONS}

Studies of epidemiology and pathology have clearly shown that, when maximum expiratory flow is normal (GOLD 0), the symptoms of chronic bronchitis do not increase the risk for progression to the more severe stages of COPD. However, the presence of these same symptoms in persons who have reached the severe (GOLD 3 ) and very severe (GOLD 4) stages of COPD predict both a more rapid decline in lung function and more frequent acute exacerbations of COPD. Studies from several sources indicate that the innate defence system of the lungs is damaged early in the course of COPD, and that this damage to the innate system is associated with colonisation and infection of the lower airways in GOLD stages 3 and 4 where histological evidence of a sharp increase in the adaptive immune response appears. The association between bronchial hyperresponsiveness and the appearance of airflow limitation serves as a marker for the later appearance of airflow limitation, possibly because it reflects remodelling of the peripheral airways. Tests that are easier to perform than bronchial responsiveness that could provide a precise estimate of the risk for developing COPD would clearly be helpful. Perhaps the current genetic approach to the study of COPD will provide markers to identify the 15$20 \%$ of smokers who will progress to severe disease as well as the means to prevent this inexorable progression.

\section{Authors' affiliations}

J Vestbo, Department of Cardiology and Respiratory Medicine, Hvidovre University Hospital, Hvidovre, Denmark; and North West Lung Centre, South Manchester University Hospital Trust, Manchester, UK

J C Hogg, James Hogg iCAPTURE Centre for Cardiovascular and Pulmonary Research, University of British Columbia and St Paul's Hospital, Vancouver, Canada

Competing interests: none.

\section{REFERENCES}

1 Pauwels R, Buist A, Calverley P, et al. Global strategy for the diagnosis, management and prevention of chronic obstructive pulmonary disease. $\mathrm{NHLBI} / \mathrm{WHO}$ global initiative for chronic obstructive lung disease (GOLD) workshop summary. Am J Respir Crit Care Med 2001;163:1256-76.

2 Celli BR, MacNee W, on behalf of the task force group. Standards for the diagnosis and treatment of patients with COPD: a summary of the ATS/ERS position paper. Eur Respir J 2004;23:932-46.

3 Pauwels RA, Rabe KF. Burden and clinical features of chronic obstructive pulmonary disease (COPD). Lancet 2004;364:613-20.

4 Brumfitt W, Willoghby MLN, Bromley LL. An evaluation of sputum examination in chronic bronchitis. Lancet 1957;ii:1306-9.

5 Thurlbeck WM, Angus GE. The relationship between chronic bronchitis and emphysema as assessed morphologically. Am Rev Respir Dis 1963;87:815-9.

6 Medical Research Council's Committee on the Aetiology of Chronic Bronchitis. Standardised questionnaires on respiratory symptoms. BMJ 1960;2:1665.

7 Fletcher CM, Tinker CM. Chronic bronchitis. A further study of simple diagnostic methods in a working population. BMJ 1961;1:1491-8.

8 Fletcher CM, Peto R, Tinker CM, et al. The natural history of chronic bronchitis and emphysema. Oxford: Oxford University Press, 1976.

9 Vestbo J, Lange P. Can GOLD stage 0 provide information of prognostic value in chronic obstructive pulmonary disease? Am J Respir Crit Care Med 2002; 166:329-32.

10 Vestbo J, Prescott E, Lange P, and the Copenhagen City Heart Study Group. Association of chronic mucus hypersecretion with $\mathrm{FEV}_{1}$ decline and COPD morbidity. Am J Respir Crit Care Med 1996;153:1530-5.
11 Hogg JC, Chu F, Utokaparch S, et al. The nature of small-airway obstruction in chronic obstructive pulmonary disease. N Engl J Med 2004;350:2645-53.

12 Donaldson GC, Seemungal TAR, Patel IS, et al. Longitudinal changes in the nature, severity and frequency of COPD exacerbations. Eur Respir J 2003;22:931-6.

13 Kanner RE, Anthonisen NR, Connett JE for the Lung Health Study Research Group. Lower respiratory illnesses promote $\mathrm{FEV}_{1}$ decline in current smokers but not ex-smokers with mild chronic obstructive pulmonary disease. Am J Respir Crit Care Med 2001;164:358-64.

14 Donaldson GC, Seemungal TAR, Bhowmik A, et al. Relationship between exacerbation frequency and lung function decline in chronic obstructive pulmonary disease. Thorax 2002;57:847-52.

15 Sethi S, Evans N, Grant BJB, et al. New strains of bacteria and exacerbations of chronic obstructive pulmonary disease. N Engl J Med 2002;347:465-71.

16 Seemungal T, Harper-Owen R, Bhowmik A, et al. Respiratory viruses, symptoms, and inflammatory markers in acute exacerbations and stable chronic obstructive pulmonary disease. Am J Respir Crit Care Med 2001; 164:1618-23.

17 Wilkinson TMA, Patel IS, Wilks $M$, et al. Airway bacterial load and FEV decline in patients with chronic obstructive lung disease. Am J Respir Crit Care Med 2003; 167:1090-5

18 Banerjee D, Khair OA, Honeybourne D. Impact of sputum bacteria on airway inflammation and health status in clinical stable COPD. Eur Respir J 2004;23:685-91.

19 Voelkel N, Taraseviciene-Stewart L. Emphysema: an autoimmune disease? Proc Am Thorac Soc 2005;2:23-5

20 Agusti A, MacNee W, Donaldson K, et al. Hypothesis: Does COPD have an autoimmune component? Thorax 2003;58:832-4.

21 Mullen JB, Wright JL, Wiggs BR, et al. Reassessment of inflammation of airways in chronic bronchitis. BMJ 1985;291:1235-9.

22 Saetta M, Turato G, Facchini FM, et al. Inflammatory cells in the bronchial glands of smokers with chronic bronchitis. Am J Respir Crit Care Med 1997; 156:1633-9.

23 De Marco R, Accordini S, Cerveri I, et al. Group. An international survey of chronic obstructive pulmonary disease in young adults according to GOLD stages. Thorax 2004;59:120-5.

24 Mannino DM, Buist AS, Petty TL, et al. Lung function and mortality in the United States: data from the First National Health and Nutrition Examination Survey follow up study. Thorax 2003;58:388-93.

25 Ryder RC, Dunnill MS, Anderson JA. A quantitative study of bronchial mucous gland volume, emphysema and smoking in a necropsy population. J Pathol 1971;104:59-71.

26 Hogg JC, Wright JL, Wiggs BR, et al. Lung structure and function in cigarette smokers. Thorax 1994;49:473-8.

27 Thurlbeck WM, Müller NL. Emphysema: definition, imaging, and quantification. Am J Roentgenol 1994;163:1017-25.

28 Hill C, van Beek EJR. MRI of the chest: present and future. Imaging 2004;16:61-70.

29 Dirksen A, Friis $M$, Olesen KP, et al. Progress of emphysema in severe alpha 1 -antitrypsin deficiency as assessed by annual CT. Acta Radiol 1997:38:826-32.

30 Macklem PT, Mead J. Resistance of central and peripheral airways measured by the retrograde cathether. J Appl Physiol 1967;22:395-401.

31 Hogg JC, Macklem PT, Thurlbeck WM. Site and nature of airways obstruction in chronic obstructive lung disease. N Engl J Med 1968;278:1355-60.

32 Yanai M, Sekizawa K, Ohrui T, et al. Site of airway obstruction in pulmonary disease: direct measurement of intrabronchial pressure. J Appl Physiol 1992;72:1016-23.

33 van Braband $T$, Cauberghs $M$, Verbeken $E$, et al. Partitioning of pulmonary impedance in excised human and canine lungs. J Appl Physiol 1983:55:1733-42.

34 Mead J. The lung's "quiet zone". N Engl J Med 1970;282:1318-9.

35 Buist AS, Vollmer WM, Johnson LR, et al. Does the single-breath $\mathrm{N}_{2}$ test identify the smoker who will develop chronic airflow limitation? Am Rev Respir Dis 1988;137:293-301.

36 Orie NGM, Sluiter HJ, de Vries K, et al. The host factor in bronchitis. In: Orie NGM, Sluiter HJ, eds. Bronchitis: an international symposium. Assen, Netherlands: Royal van Gorcum, 1961

37 Retamales I, Elliott WM, Meshi B, et al. Amplification of inflammation in emphysema and its association with latent adenoviral infection. Am J Respir Crit Care Med 2001;164:469-73.

38 Rijcken B, Schouten JP, Xu X, et al. Airway hyperresponsiveness to histamine associated with accelerated decline in $\mathrm{FEV}_{1}$. Am J Respir Crit Care Med 1995; 151:1377-82.

39 O'Connor GT, Sparrow D, Weiss ST. A prospective longitudinal study of methacholine airway responsiveness as a predictor of pulmonary-function decline: the Normative Aging Study. Am J Respir Crit Care Med 1995; 152:87-92

40 Tashkin DP, Altose MD, Connett JE, et al. Methacholine reactivity predicts changes in lung function over time in smokers with early chronic obstructive pulmonary disease. Am J Respir Crit Care Med 1996;153:1802-11.

41 Hospers JJ, Postma DS, Rijcken B, et al. Histamine airway hyperresponsiveness and mortality from chronic obstructive pulmonary disease: a cohort study. Lancet 2000;356:1313-7.

42 Lange $\mathbf{P}$, Parner J, Vestbo J, et al. A 15-year follow-up of ventilatory function in adults with asthma. N Engl J Med 1998;339:1 194-200.

43 Fabbri LM, Romagnoli M, Corbetta L, et al. Differences in airway inflammation in patients with fixed airflow obstruction due to asthma or chronic obstructive pulmonary disease. Am J Respir Crit Care Med 2003;167:418-24.

44 Postma DS, Boezen HM. The rationale for the Dutch hypothesis. Chest 2004; 126:96-104S 